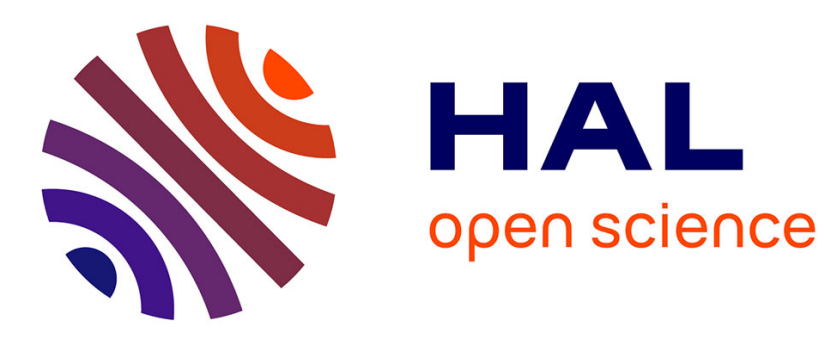

\title{
Elaboration of a common frame of reference in Collaborative Virtual Environments
}

\author{
Amine Chellali, Isabelle Milleville-Pennel, Cédric Dumas
}

\section{To cite this version:}

Amine Chellali, Isabelle Milleville-Pennel, Cédric Dumas. Elaboration of a common frame of reference in Collaborative Virtual Environments. European conference on Cognitive ergonomics: ECCE 2008, Sep 2008, Funchal, Madeira, Portugal. pp.83-90, 10.1145/1473018.1473045 . hal-00470443

\section{HAL Id: hal-00470443 \\ https://hal.science/hal-00470443}

Submitted on 20 May 2010

HAL is a multi-disciplinary open access archive for the deposit and dissemination of scientific research documents, whether they are published or not. The documents may come from teaching and research institutions in France or abroad, or from public or private research centers.
L'archive ouverte pluridisciplinaire HAL, est destinée au dépôt et à la diffusion de documents scientifiques de niveau recherche, publiés ou non, émanant des établissements d'enseignement et de recherche français ou étrangers, des laboratoires publics ou privés. 


\section{Elaboration of a common frame of reference in Collaborative Virtual Environments}

\author{
Amine Chellali \\ EMN - IRCCYN \\ 4 rue A. Kastler \\ 44307 Nantes CEDEX 3 \\ Amine.chellali@emn.fr
}

\author{
Isabelle Milleville-Pennel \\ IRCCYN \\ 1, rue de la Noë - BP 92101 \\ 44321 Nantes CEDEX 03 \\ Isabelle.Milleville- \\ Pennel@irccyn.ec-nantes.fr
}

\author{
Cédric Dumas \\ EMN - IRCCYN \\ 4 rue A. Kastler \\ 44307 Nantes CEDEX 3 \\ Cedric.dumas@emn.fr
}

\begin{abstract}
Motivation - To design virtual environments that support collaborative activities.

Research approach - An experimental approach in which 44 students were asked to work in pairs to reconstruct five 3D figures.

Findings/Design - The results show that including a contextual clue in virtual environments improves collaboration between operators.
\end{abstract}

Research limitations - Further investigative work must be carried out to extract accurate female collaboration profiles.

Originality/Value - The results enable three collaboration profiles to be identified. They also allow the extraction of some characteristics of a contextual clue which can be added to a virtual environment to improve collaboration.

Take away message - The contents of a collaborative virtual environment influences the way that users collaborate.

\section{Keywords}

Virtual environment, collaboration, common frame of reference, 3D interface.

\section{INTRODUCTION}

When confronted with a collaborative situation in the real world, operators elaborate and maintain mental representations that fit with their environment. In order to do that, they exchange information through different sensory modalities (vision, audition, haptic). However, in Virtual Environments (VE), the means of communication are limited, particularly when operators are remote from each other. Thus, VE must give other information that may be used by participants to build an efficient common frame of reference: common representation for actions and for the spatial position of objects.

In this paper, we will define some important concepts: Collaborative Virtual Environment (CVE) and Common Frame of Reference (CFR). Then, we will discuss difficulties in developing mutual understanding within a VE. In the second part of this paper, we will present a study about the impact that a stable visual landmark has on CFR construction and resulting collaboration profiles.

\section{COLLABORATIVE VIRTUAL ENVIRONNEMENTS}

CVEs are digital spaces in which distant users can meet, share virtual objects and work together. They are used in many areas, such as e-learning, CAD, training and entertainment (Snowdon et al. 2001). CVEs can lead to a reduction in costs (by using a teleconference system, for example) and risks relative to some applications (e.g. medical training and the nuclear industry). However, the design of VEs which can support collaboration remains an issue.

\section{COMMON FRAME OF REFERENCE}

In a collaborative situation, peers work together and share a common goal (although in some cases, the common goal is not obvious). This situation involves interactions between participants, synchronous communication and negotiation (Dillenbourg, 1999). To reach mutual understanding, operators have to define and maintain a consistent representation of the situation. This representation defines their CFR (Hoc \& Blosseville 2003). Using this CFR, peers can act simultaneously with different but complementary actions. In a surgery, for example, each operator on the medical staff team performs a different task and team members must anticipate each other's actions to prevent interference.

The notion of CFR meets other concepts defined in the literature, such as: common ground (Clark \& Brennan 1991), joint problem space (Roschelle \& Teasley 1995) and mutual modelling (Dillenbourg, 1999). All these concepts underline the importance of constructing and maintaining a shared comprehension of a problem and its role in collaboration. Each participant in the collaborative process must compare their own representation to those of his/her partners. They must be aware of any possible divergence of opinion or representations and must also be aware of how to overcome this. Hence partners use a communication process in which they exchange signs of understanding. Clark and Brennan called this the grounding process (Clark \& Brennan, 1991). The communication is, therefore, the engine of collaboration. It consists of an exchange of information between participants. The 
means of communication can be divided into two complementary components: an explicit component (verbal or written communication) and an implicit component (such as body movements, facial expressions, touch and eye contact). In the grounding process, the partners make a collaborative effort to understand each other. To improve the efficiency of the communication, this effort must be minimized (Clark \& Brennan, 1991). Thus, operators have to exploit the features of their environment: common spatial representation and knowledge of the world ("up" is towards the sky), their proximity to the environment in which they operate, their sense of the presence of others, and an awareness of their ongoing activities (Harrison \& Dourish, 1996).

\section{RELATED WORK}

In the real world, the features listed above allow people to organise their behaviours to achieve optimum collaboration. However, according to characteristics inherent to VEs, some features become hard to exploit directly: operators don't necessarily share the same viewpoints about the environment; partners are not close to each other; the sharing of information about each other's ongoing activities is limited and the objects of the interaction are not close to operators. This may constrain partners' communication. Furthermore, the means of communication in a VE are often reduced to their explicit component. For example, body movements, touch and facial expressions are hard to reproduce faithfully in VEs. This implies a new form of collaborative interaction which has to fit VE's particularities. In fact, in a CVE, verbal communication becomes the main (sometimes the only) resource used to exchange information and construct a CFR.

There is an increasing interest in the problems of mutual understanding in VE within the literature: Kraut et al. (2003) showed that the sharing of a visual space increases the use of pointing and deictic expressions (that, here...) and thus improves collaboration. Axelsson et al. (2003) compared the construction of a common ground between peers in a VE taking into account the immersive virtual reality system being used. Results showed that users tried to find the best strategy to reduce communication costs. In a study of asymmetrical systems and problems related to differences in viewpoint and restrictions between users (Hindmarsh et al., 1998), the authors found that these restrictions impeded collaboration. This was because partners were not aware of the possibilities and constraints of their collaborators. They went on to suggest clues about the partners' actions in the VE in order to avoid these problems and to improve collaboration. On the other hand, Spante et al. (2004) showed that a partner's knowledge about the possibilities and constraints of his collaborator can improve collaboration.

Analysis of these results shows that sharing visual information is necessary to reduce communication costs in a collaborative situation. However, this visual information needs to be broadened to improve CFR construction. Furthermore, keeping a partner informed about your own ongoing activities may improve CFR construction. Finally, designers of CVEs must take into account the different reference systems used by each operator (cf. next section). Indeed, even if the operators do not share the same viewpoint, highlighting their common knowledge of the VE (e.g. the relative positions of objects) may reduce misunderstanding.

\section{REFERENCE SYSTEMS}

The description of an operator's action is dependent on his viewpoint of the environment and can use one of the following systems (Bridgeman, 1999):

(a) An egocentric reference system in which actions and objects are located according to the operator's body or some parts of his body. This system is preferred when performing actions, such as grasping or moving an object.

(b) An exocentric reference system, i.e. one that refers to the elements of the operator's environment. It is well adapted for making a spatial description of a room or for reading a map. This system involves mental rotations which make objects fit with the operator's point of view.

An operator can also use a relative exocentric system. In fact, he/she can specify an action according to an element of his/her environment, but this referenciation has meaning only if it is related to his/her viewpoint (e.g., the sentence "put the pen behind the book" will have meaning only if the operator is in front of the book).

\section{Which reference system in CVE?}

In spite of the importance of reference systems in CVE and their influence on CFR construction, few research studies deal with this problem. However, some studies can help us to define our research hypotheses.

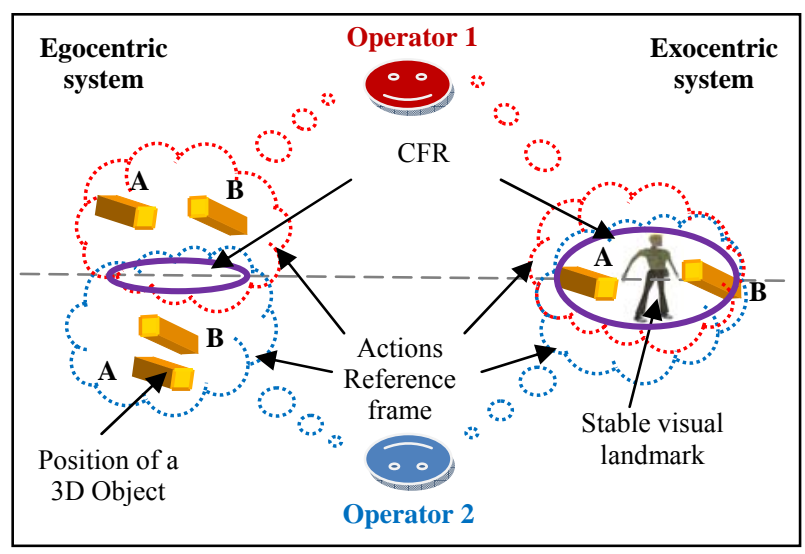

Figure1: in an egocentric system, for operator 1, object $A$ is on his right and object $B$ on his left. For operator 2, object $A$ is in the front and object $B$ is behind. In an exocentric system for both operators, the object $A$ is on the right of the fixed reference (the virtual character) and object $B$ on its left.

According to Kimura (2001), male and female operators have different spatial abilities. Several experiments 
show a best performance for men, particularly with regard to mental rotations. They usually use geometric properties of their space to position themselves. On the other hand, women are better able to remember marks on a path or the positions of objects drawn on a paper. These differences can be explained by the use of different reference systems by males and females. They can lead to different resolution strategies for men and women carrying out $3 \mathrm{D}$ object-handling tasks.

On the other hand, Roberts and Aman (1993) have shown that in 3D environments, operators tend to use an egocentric reference system. However, in a collaborative activity, because of the divergence of operators' views, specifying actions in an egocentric system (which is specific to each operator) can lead to misunderstandings and/or antagonistic actions. Moreover, in a VE containing similar objects, it is difficult to reference them unambiguously (cf. Figure 1). This complicates the construction of a CFR and impedes collaborative activity.

It can therefore be assumed that when the situation becomes sufficiently complex (different viewpoints, multiple manipulations of an object, etc.), operators prefer voluntary use of the exocentric system; (when it is permitted by the presence of contextual clues in the environment). An example of this can be found in a study by Blouin et al. (1993) on pointing movement in visuo-kinaesthetic conflicting situations. This reference system can lead to better coordination in the planning of actions and reduces the ambiguities for objects' referenciation. Moreover, gender can also influence the way operators construct their CFR using reference systems. In fact, an exocentric system requires that mental rotations be performed. Hence, males may use this system more intuitively than females.

In this exploratory study, we will look at the problem of how operators choose a reference system, focussing in particular on how they describe their actions.

By studying collaboration strategies between operators, our purpose is to show:

- The role of stable visual landmarks in the visual space to locate objects according to these landmarks and not only in relation to the operator's viewpoint (or his/her position).

- Impact of participants' gender on the way they use reference systems and construct their CFR.

- Impact of reference systems being used on the profiles of collaboration that can occur between operators.

\section{HYPOTHESES}

H1. Operators use more exocentric and relative exocentric systems in the presence of a Stable Visual Landmark (SVL).

H2. The use of exocentric and relative exocentric systems in the presence of the SVL is less obvious for females than for males.
H3. The use of an exocentric system allows a wider CFR between operators.

H4. There is a link between the reference systems being used and the types of partnerships that are developed.

\section{METHOD}

Forty-four students (20 to 27 years old) were divided into 22 pairs (10 female pairs and 12 male pairs). No subject had prior knowledge of the VE. Participants of each pair did not know each other before the experiment and met 5 minutes before the session started.

The CVE used in this experiment consists of a 3D model to reproduce using 6 different white tetraminos ${ }^{1}$ (cf. Figure 2). The subjects could interact with these tetraminos using joypads. Two users could move two different tetraminos at the same time.

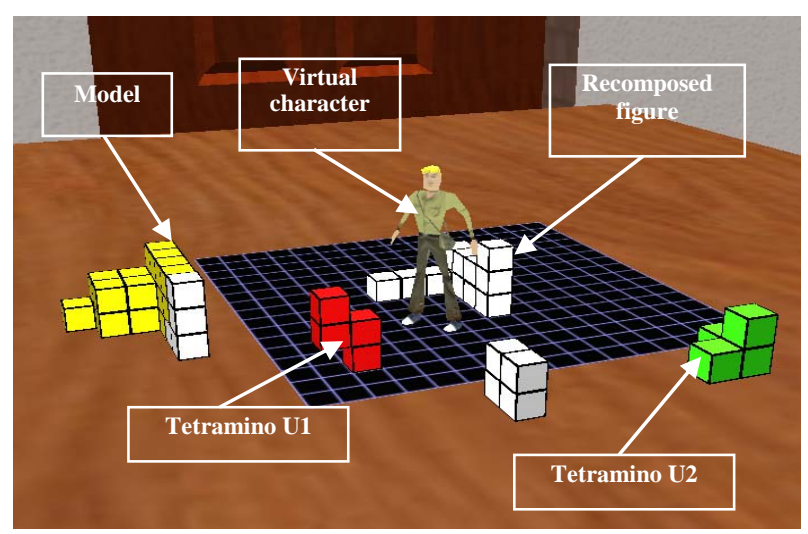

Figure 2: The virtual interface

\section{Stable Visual Landmark}

According to experimental conditions (see Variables and Measures section below) a virtual character representing a SVL was placed in the scene's centre (cf. Figure 2). The choice of a humanoid figure was not incidental. Indeed, its lateralization (he has one right, one left, one front side and one rear side) is natural and allows operators to locate objects in relation to him. This relative location remains usable and understandable by both operators, even if they don't share the same view.

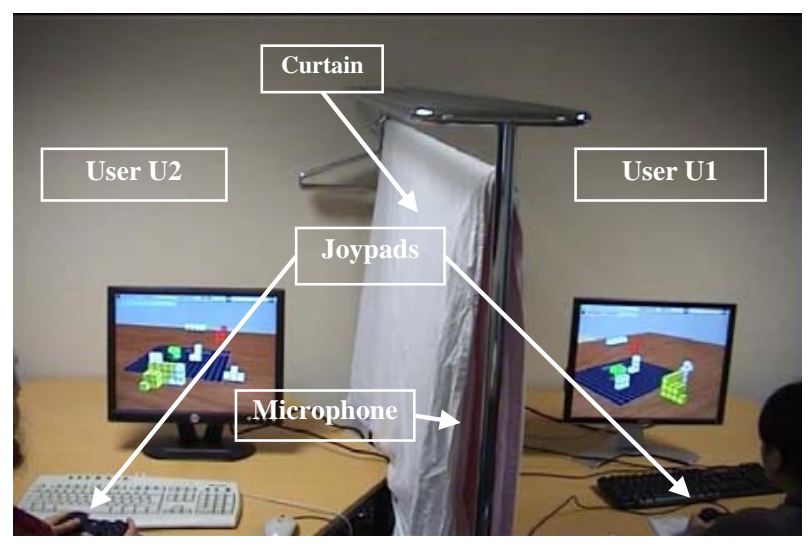

Figure 3: Experimental design

${ }^{1}$ A tetramino is a geometric figure which consists of four cubes, each having at least one side shared with another (Tetris game figures). 


\section{Procedure}

Each subject was seated in front of an LCD screen and held a joypad. Participants couldn't see each other's screen (cf. Figure 3). However, they were allowed to communicate verbally. Before sessions, subjects had a number of trial sessions to become familiar with the interface.

The subjects were asked to work together to reproduce 5 models (cf. Figure 4). For each model, the subjects' starting viewpoints were different from each other. They were allowed to modify their viewpoint during the task. For each model, the $1^{\text {st }}$ tetramino (in white) was correctly placed in the figure.
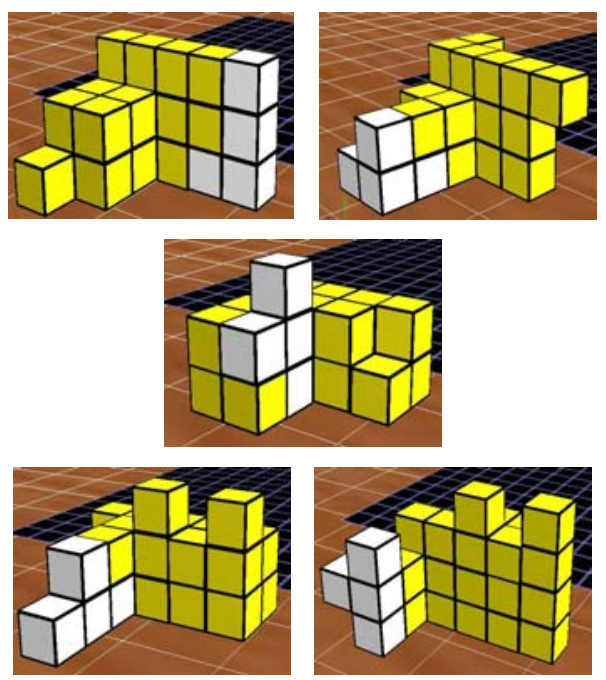

Figure 4: Models to reproduce

\section{Variables and Measures}

Two independent factors were manipulated (cf. Table 1):

- SVL with two modalities: Presence/Absence (P-SVL, A-SVL).

- Participants' gender with two modalities: Male/Female (M, F).

\begin{tabular}{|c|c|c|}
\hline Variables & P-SVL & A-SVL \\
\hline Male & M/ P-SVL: 6 pairs & M/ A-SVL: 6 pairs \\
\hline Female & F/ P-SVL: 5 pairs & F/ A-SVL: 5 pairs \\
\hline
\end{tabular}

Table 1: Composition of the participants' groups

Measures of task performance included task completion time and the number of errors.

As verbal communications were the main measures to evaluate collaboration, video and audio recordings of the sessions were realized. All dialogues were faithfully transcribed. Subsequently, verbalizations were filtered by eliminating conversations that did not concern the task. Finally, the filtered verbalizations were analysed according to 3 measures:

- The use of the 3 reference systems (egocentric, exocentric and relative exocentric)
- The use of pronouns: personal ("I", "You") and impersonal ("We", "One").

- Verbalization types: conversations were classified into 15 categories (cf. Table 2) to get a detailed analysis of verbalizations.

\section{Statistical analysis}

The data were analyzed using two types of statistical tests:

- The frequency of observation of behaviour within the same group (use of reference systems and pronouns) was compared with the $\chi 2$ test.

- Given the small number of participants in each group, we were unable to perform ANOVA to compare averages. Only t Student tests were used.

\section{RESULTS}

\section{Performance}

The results showed that males were faster than females $(\mathrm{t}(20) \mathrm{p}=0.002)$ to perform the task. However, there were no significant differences between the groups PSVL and A-SVL (t(20) p=0.658; cf. Figure 5).

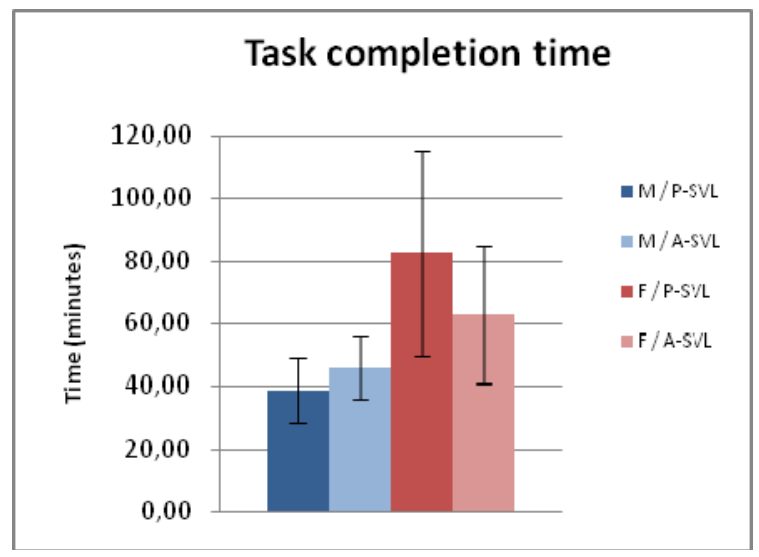

Figure 5: Task completion time

Concerning errors, the results showed that males made fewer errors than females. They made fewer errors in the P-SVL condition than in the A-SVL condition ( $t(9)$ $p=0.02$ in $\mathrm{P}-\mathrm{SVL}$ condition and $\mathrm{t}(9) \mathrm{p}=0.75$ in $\mathrm{A}-\mathrm{SVL}$ condition; cf. Figure 6).

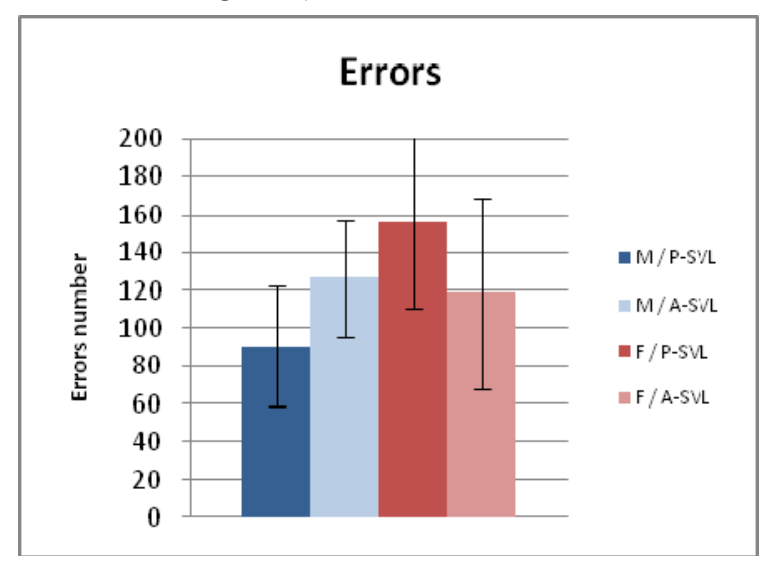

Figure 6: Amount of errors 


\section{Verbalization analysis}

\section{Reference systems}

Regarding the differences between the groups P-SVL and A-SVL: females favoured the use of the egocentric system and even more so in the A-SVL condition $\left(\chi_{\mathrm{k} \text { - }}^{2}\right.$ ${ }_{1}=0.1747$ and $\chi_{\mathrm{k}-1}^{2}=0.7722 ; \mathrm{p}<0.05$, in P-SVL and the ASVL conditions respectively; cf. Figure 7-a).

Males used more exocentric and relative exocentric systems in the P-SVL condition and more egocentric systems in the A-SVL condition $\left(\chi_{\mathrm{k}-1}^{2}=0.03139\right.$ and $\chi_{\mathrm{k} \text { - }}^{2}$ ${ }_{1}=0.4898 ; \mathrm{p}<0.05$, in the P-SVL and A-SVL conditions respectively; cf. Figure 7-b).

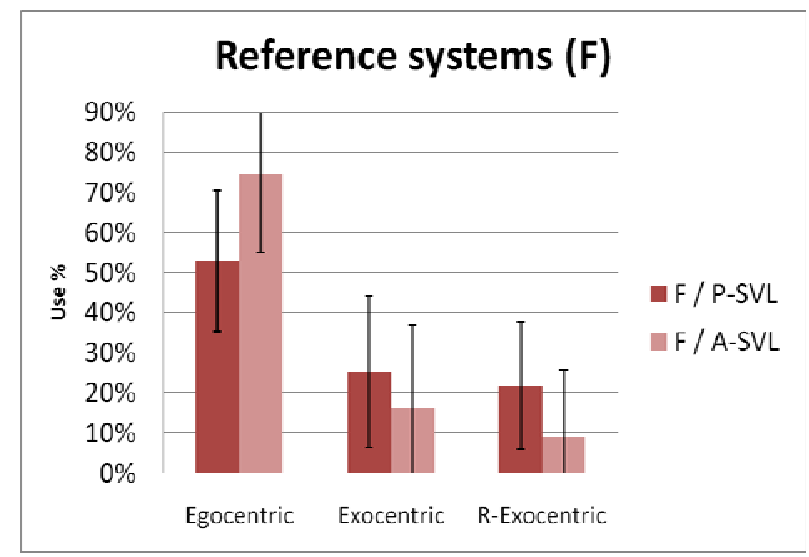

Figure 7-a: Use of reference systems (females)

Regarding the differences between males and females: females used the egocentric system more than males $(t(20) \mathrm{p}=0.019$; cf. Figure $7 \mathrm{a}$ and $\mathrm{b})$. Males used the relative egocentric system more than females $(\mathrm{t}(20)$ $\mathrm{p}=0.00007$; cf. Figure $7 \mathrm{a}$ and $\mathrm{b}$ ).

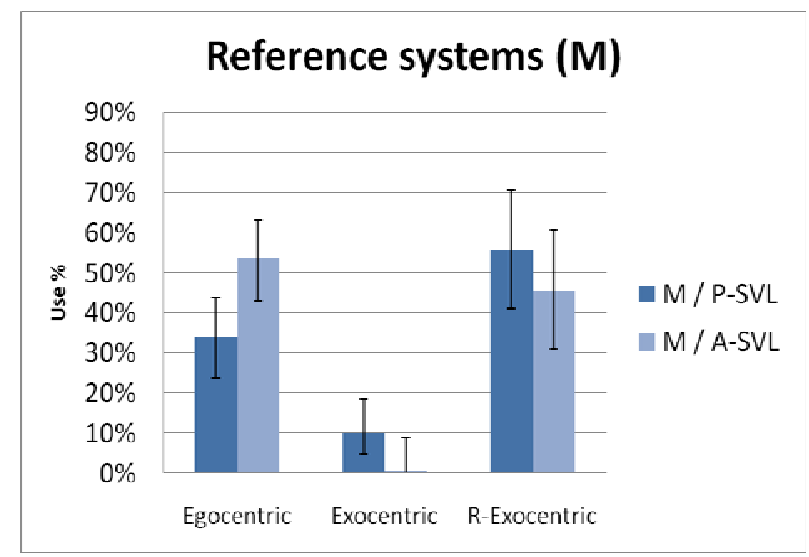

Figure 7-b: Use of reference systems (males)

\section{Pronouns}

The results showed that males operated in a more personal way (use of personal pronouns "I" and "you") even more in the A-SVL condition $\left(\chi_{\mathrm{k}-1}^{2}=0.0631\right.$; $\mathrm{p}>0.05$ and $\chi_{\mathrm{k}-1}^{2}=0.1094 ; \mathrm{p}<0.05$, and in the P-SVL and A-SVL conditions respectively; cf. Figure 8).

Females tended to use more impersonal pronouns ("one" and "we") than personal ones in the P-SVL condition $\left(\chi_{\mathrm{k}-1}^{2}=0.0403\right.$ and $\chi_{\mathrm{k}-1}^{2}=0.0720 ; \mathrm{p}>0.05$, and in the P-SVL and A-SVL conditions respectively; cf. Figure 8-a).

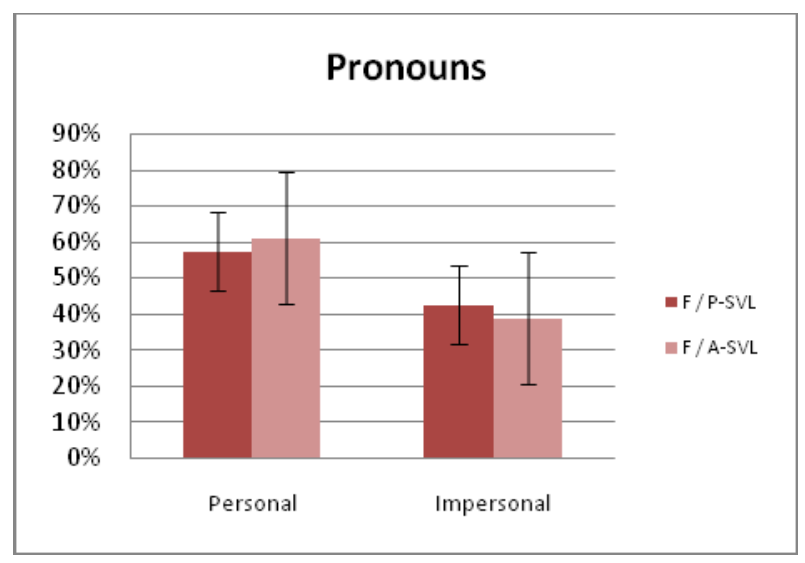

Figure 8-a: Figure 8: Use of pronouns (females)

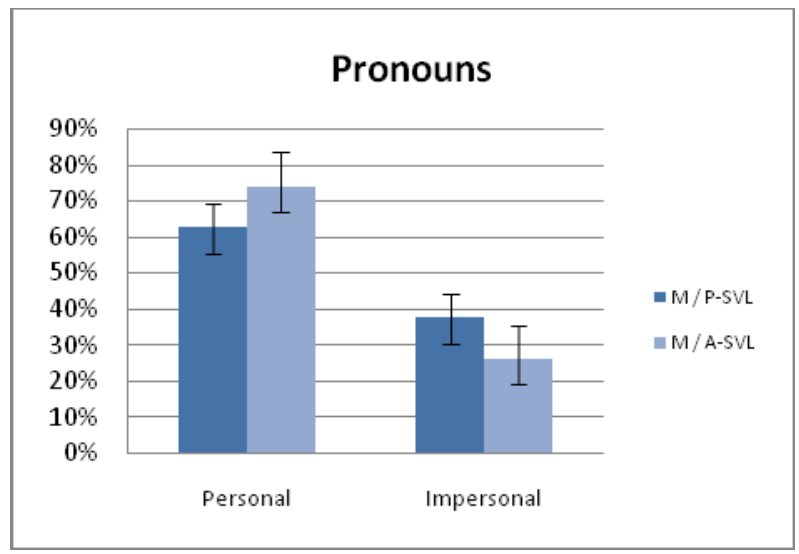

Figure 8-b: Use of pronouns (males)

Types of verbalizations

Males' conversations involved more: comments on their own actions (C3, cf. Table 2; $\mathrm{t}(20) \mathrm{p}=0.005)$ and task sharing expressions (C15-a; $\mathrm{t}(20) \mathrm{p}=0.067$ and $\mathrm{C} 15-\mathrm{b}$; $t(20) \mathrm{p}=0.044$ ) than females' conversations (cf. Figure 9).

Females' conversations involved more: comments on their partner's actions (C2; t(20) $\mathrm{p}=0.027)$, explicit misunderstanding expressions (C9; $\mathrm{t}(20) \mathrm{p}=0.043)$ and reflections on the upstream solution $(\mathrm{C} 14 \mathrm{a} ; \mathrm{t}(20)$ $\mathrm{p}=0.0002$ ) than males' conversations (cf. Figure $9 \mathrm{a}$ and b).

Regarding the differences between the P-SVL and ASVL groups: In the A-SVL condition, participants provide more individual reflection clues than in the $\mathrm{p}$ SVL condition ( $\mathrm{t}(20) \mathrm{p}=0,048$ ) (cf. figure 9). In addition, the presence of the SVL has a varied influence, depending on the participants' gender:

For females, no significant differences were observed between the P-SVL and A-SVL groups (cf. Figure 9-a).

In contrast, two distinct profiles were observed for males: in the P-SVL condition, conversations involved more descriptions preceding an action $(\mathrm{C} 1 ; \mathrm{t}(10)$ $\mathrm{p}=0.011)$, approvals of the partner's actions (C5; $\mathrm{t}(10)$ 
$\mathrm{p}=0.032)$ and symmetrical task-sharing expressions $(\mathrm{C} 16 \mathrm{a} ; \mathrm{t}(10) \mathrm{p}=0.024)$ than females' conversations in the A-SVL condition (cf. Figure 9-b).

In the A-SVL condition, conversations involved more leadership expressions $(\mathrm{C} 10 ; \mathrm{t}(10) \mathrm{p}=0.028)$ and asymmetrical task-sharing expressions $(\mathrm{C} 15 \mathrm{~b} ; \mathrm{t}(10)$ $\mathrm{p}=0.031$ ) than conversations in the P-SVL condition (cf. Figure 9-b).

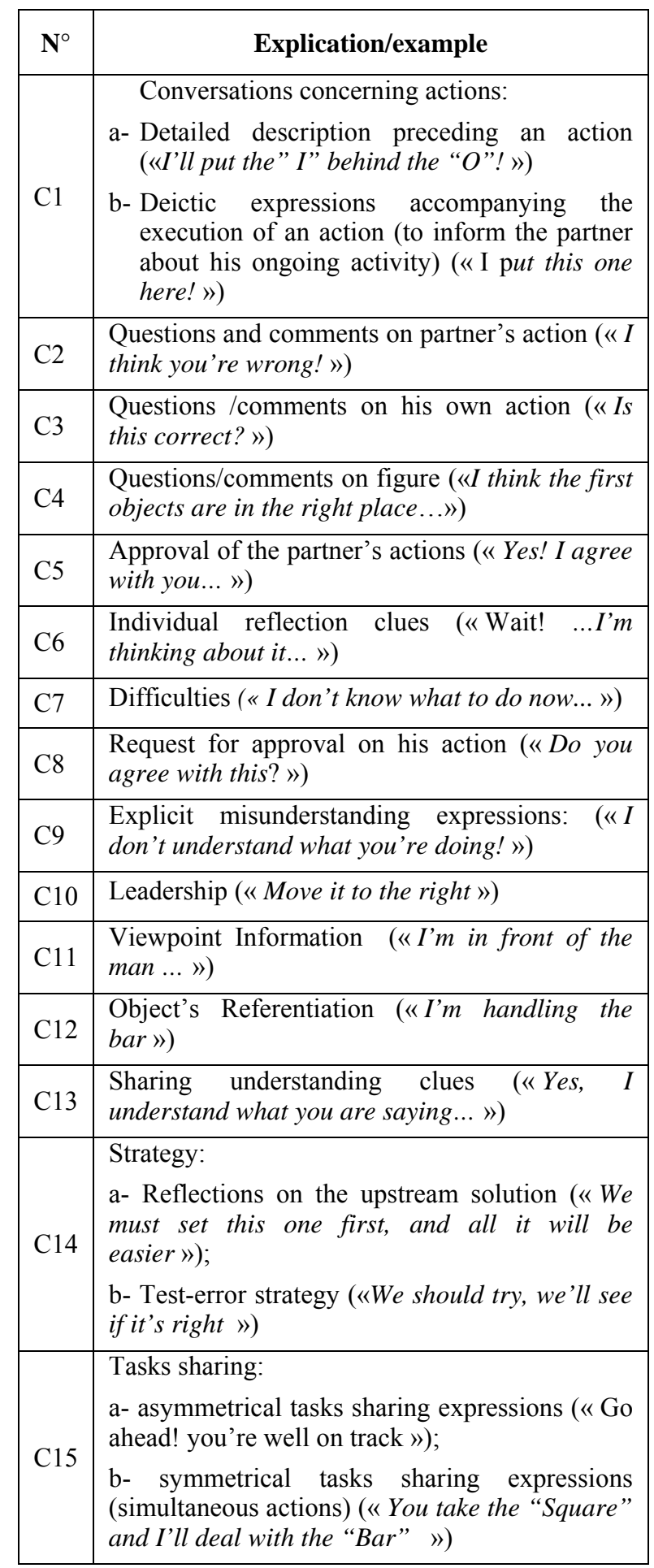

Table 2: Verbalization categories

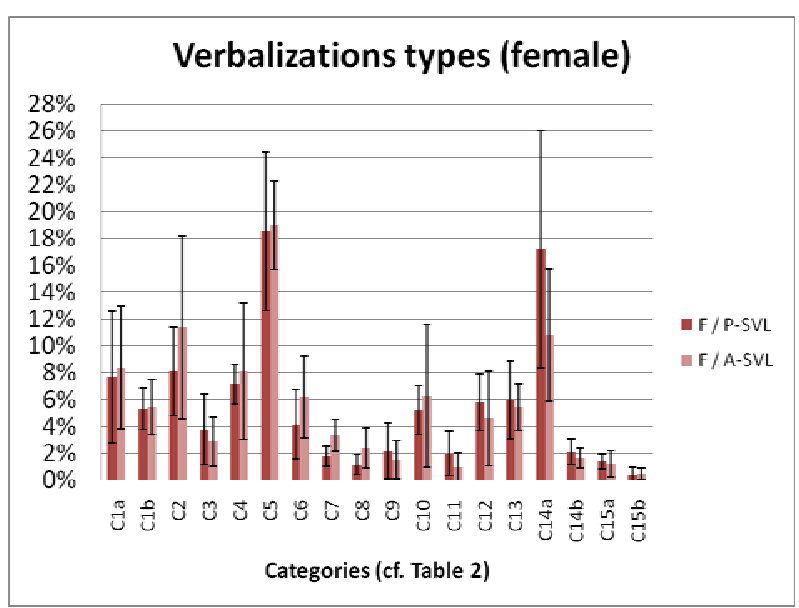

Figure 9-a: Types of verbalization (females)

Verbalizations types (male)

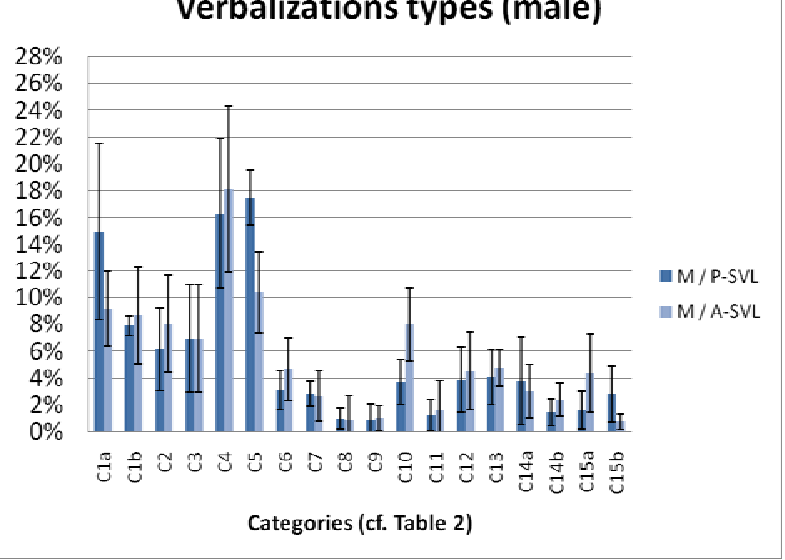

Figure 9-b: Types of verbalization (males)

\section{DISCUSSION}

\section{Performance}

Results show that males were faster than females. The longer completion time for females is accompanied by an increase in the number of errors. This shows that females find it more difficult to accomplish the task. This can be related to (i) the task requirements and the difficulties of females to perform mental rotations, as suggested by Kimura (2001) and (ii) to their use of an egocentric reference system. The latter is consistent with the results observed in male groups. Indeed, males made more errors in the A-SVL condition, in which they used a more egocentric reference system.

\section{Influence of the SVL}

The results show that males were influenced by the SVL. Indeed, they used a more egocentric system in the A-SVL condition and a more exocentric and relative exocentric system in the P-SVL condition. These results are consistent with those found by Blouin et al. (1993). In fact, male subjects prefer to use the SVL as a reference when it is present. On the other hand, females are less sensitive to the SVL presence and don't use it as a reference. This can be explained by their difficulties in performing mental rotations, as suggested by Kimura (2001). Mental rotations are necessary to use an exocentric system. Thus, females prefer to use an 
egocentric system which is easier for them. We conclude that hypothesis $\mathrm{H} 1$ is true only for male participants. Otherwise, this result confirms hypothesis $\mathrm{H} 2$.

\section{CFR Construction}

In the presence of the SVL, males described their actions in advance, had more positive feedback from their partner, and acted more often in symmetry. In the absence of the SVL they had more negative feedback (comments and questions) and tried more often to control their partner. These results suggest a more efficient CFR for males. Indeed, descriptions preceding actions and positive feedback can be interpreted as signs of understanding between the partners. On the other hand, comments and questions about the actions of the partner can be seen as signs of disagreement and misunderstanding between partners. That is why some participants took the initiative by leading their partners to their own solutions. This also explains the asymmetrical task-sharing which occurred. For females, it is difficult to say if they have a more efficient CFR in one condition than another because there are very few differences between groups. The hypothesis H3 for male pairs can be validated. However, there is a need for further investigation with regard to female pairs.

\section{Collaboration profiles}

Three collaboration profiles can be extracted:

\section{Teamwork male profile}

In the presence of the SVL, males have a group profile that features more discussions about their actions, positive feedback, parallel actions and fewer attempts to control their partner. This is associated with the use of exocentric and relative exocentric reference systems and impersonal pronouns.

\section{Individualistic male profile}

In the absence of the SVL, males are more "personal", with fewer discussions about actions, more individual reflections cues, asymmetrical task-sharing, more negative feedback and more attempts to control their partner. This is associated with greater use of the egocentric reference system and personal pronouns.

\section{Female profile}

Females are less sensitive to the presence of the SVL. However, they are less individualistic since they used more impersonal pronouns than males. Unfortunately, the variability of the results for female groups prevents the extraction of an accurate profile.

The two male collaboration profiles depend on the reference system being used. Hence, the hypothesis H4 is validated.

\section{Additional findings}

Regarding CFR construction, it was observed that all the participants tried to take advantage of visual clues which characterize the interface. Indeed, the use of deictic expressions shows that operators used activity clues (change of colour of a tetramino when it is handled) to attract their partner's attention and to show him/her their ongoing actions. Males (in both the P-SVL and A-SVL conditions) used more deictic expressions than females. At the same time, females used more explicit misunderstanding expressions (in both the PSVL and A-SVL conditions) than males.

These results can be related to the results found by Kraut et al. (2003). In fact, operators take advantage of their shared visual space. Therefore, in some cases, they used deictic expressions when acting, instead of describing in advance their actions. This reduces misunderstandings between them and optimizes communication. The use of deictic expressions is also a way to increase collaboration, since operators are constantly informed about their partner's activity. Further investigative work must be carried out to identify the impact of informing an operator about his/her partner's activities on CFR construction.

\section{CONCLUSION}

This study is part of wider research which aims to offer some recommendations for CVE design. The results of the experiment showed a difference between females and males in the way that they collaborate on a figure reconstruction task. The results also showed that the presence of contextual clues (SVL) in the VE influenced the way participants worked together. Thus, the addition of the virtual character as a SLV in the VE has a positive effect on collaboration in the case of male users. Indeed, it improves the construction of a CFR between users and in particular for the coordination of actions.

To be effective in the construction of a CFR in a virtual scene, the visual landmark must be: literalized, fixed, visible to all users, in-scale with the scene, easy to name, easy to identify among other objects and can serve as a reference to all objects within that environment.

In a future study, we will introduce haptic devices as an additional mean of communication in the VE. The purpose of this will be to know whether it is possible to improve understanding between operators by giving them more resources with which they can inform their partners about their activities. The results of these studies will give us information on how operators work together through a VE and can be used to design CVE facilitating collaboration.

\section{ACKNOWLEDGEMENTS:}

We would like to thank students from Nantes University who agreed to participate in this experiment. The research was partially funded through the InterActeurs project (CRE 43230501) in collaboration with Orange Labs.

\section{REFERENCES}

Axelsson, AS., Abelin, Å., \& Schroeder, R. (2003). Communication in Virtual Environments: Establishing Common Ground for a Collaborative Spatial Task. The 6th International Workshop on Presence, Aalborg, Denmark, October 6-8. 2003. 
Blouin, J., Bard, C., Teasdale, N., Paillard, J., Fleury, M., Forget, R., \& Lamarre, Y. (1993). Reference systems for coding spatial information in normal subjects and a deafferented patient. Experimental Brain Research, 93, pp. 324-331.

Bridgeman, B., (1999). Separate representations of visual space for perception and visually guided behavior. In G. Aschersleben, T. Bachmann \& J. Müsseler (Eds). Cognitive Contribution to the Perception of Spatial and Temporal Events (pp. 318).

Clark, H.C. \& Brennan, S. (1991) Grounding in communication. In L. B. Resnick, J. Levine \& S. D. Teasley (Eds.), Perspectives on socially shared cognition. Washington: APA Books.

Dillenbourg, P. (1999). What do you mean by collaborative learning? In Dillenbourg (Ed.), Collaborative Learning: Cognitive and Computational Approaches: Elsevier Science/Pergamon.

Harrison, S. \& Dourish, P. (1996). Re-place-ing space: the roles of place and space in collaborative systems. In proceedings of CSCW' 96.

Hindmarsh, J., Fraser, M., Heath, C., Benford, S. \& Greenhalg, C. (1998). Fragmented Interaction: Establishing mutual orientation in virtual environments. In CSCW'98, 217-226.

Hoc J.M. \& Blosseville, J.M. (2003). Cooperation between drivers and in-car automatic driving assistance. In G.C. Van der Veer \& J.F. Hoorn (Eds.), Proceedings of CSAPC'03 (pp. 17-22).

Kraut, R. E., Fussell, S. R. \& Siegel, J. (2001). Visual information as a conversational resource in collaborative physical tasks. HCI, 18, 13-49. 2003.

Kimura, D. (2001). Cerveau d'homme et cerveau de femme ? Les aptitudes spatiales (pp. 78-79). Paris: Odile Jacob.

Roberts R. J. Jr. \& Aman, C. (1993). Developmental Differences in Giving Directions: Spatial Frames of Reference and Mental Rotation. Child Development 64 (4): 1258-70.

Roschelle, J. \& Teasley, S.D. (1995). Construction of shared knowledge in collaborative problem solving. In C. O'Malley (Ed.), CSCL. (69-97).

Snowdon, D., Churchill, E.F. \& Munro, A.J. (2001). Collaborative Virtual Environments: Digital Spaces and Places for CSCW: An Introduction. In Churchill, E.F., Snowdon, D.N. \& Munro, A.J. (eds) Collaborative Virtual Environments:Digital Places and Spaces for Interaction. London: Springer-Verlag. 3-17.

Spante, M., Schroeder, R. \& Axelsson, AS. (2004). How Putting Yourself into the Other Person's Virtual Shoes Enhances Collaboration. Proceeding of the 7th International Workshop on Presence, Valencia, Spain-, pp. 190-196. 